\title{
Monitoring human cytomegalovirus viral load in peripheral blood leuko- cytes of renal transplant recipients by a simple limiting dilution-PCR assay
}

\section{O.L. Caballero $0^{1,3}$, \\ M.C.S.L. Costa ${ }^{4}$ \\ A. Trevisan ${ }^{1}$, R.M. O Oliveira ${ }^{5}$, \\ E.A. Viotti ${ }^{6}$, E.R.F. Távora ${ }^{6}$, \\ S.S. Vilaça ${ }^{6}$, E. Sabagga ${ }^{8}$, \\ F.J. de-Paula ${ }^{8}$, P.F. Távora ${ }^{7}$, \\ G. Brasileiro-Filho', \\ L.L. Villa ${ }^{1}$ and \\ A.J.G. Simpson²}

\section{Correspondence}

A.J.G. Simpson

Laboratório de Genética do Câncer

Instituto Ludwig de Pesquisa

sobre o Câncer

Rua Prof. Antonio Prudente, 109

40 andar

01509-010 São Paulo, SP

Brasil

Fax: + 55-11-270-7001

E-mail: asimpson@node1.com.br

Research partially supported by the PADCT program, administered by FINEP. A. Trevisan is the recipient of a FAPESP fellowship, and M.C.S.L. Costa received a salary from $\mathrm{Hemagen} \mathrm{S} / \mathrm{A}$.

Received January 25, 1999 Accepted September 21, 1999

\author{
Laboratórios de ${ }^{2}$ Virologia and ${ }^{2} G$ enética do Câncer, \\ Instituto Ludwig de Pesquisa sobre o Câncer, São Paulo, SP, Brasil \\ ${ }^{3}$ Departamento de Ciências Biológicas, Faculdade de Medicina do Triângulo Mineiro, \\ U beraba, MG, Brasil \\ ${ }^{4}$ Hemagen S/A, São Paulo, SP, Brasil \\ ${ }^{5}$ Departamento de Patologia Clínica e Hemoterapia, Hospital A.C. Camargo, \\ São Paulo, SP, Brasil \\ ${ }^{6} \mathrm{H}$ ospital Felício Rocho, and ${ }^{7}$ Laboratório São Marcos, Belo Horizonte, MG, Brasil \\ ¿Unidade de Transplante Renal, Hospital das Clínicas, U niversidade de São Paulo, \\ São Paulo, SP, Brasil \\ ${ }^{9}$ Departamento de Anatomia Patológica e Medicina Legal, Faculdade de Medicina, \\ Universidade Federal de Minas Gerais, Belo Horizonte, MG, Brasil
}

\section{Abstract}

To assess the clinical relevance of a semi-quantitative measurement of human cytomegalovirus (HCMV) DNA in renal transplant recipients within the typical clinical context of a developing country where virtually $100 \%$ of both receptors and donors are seropositive for this virus, we have undertaken HCMV DNA quantification using a simple, semi-quantitative, limiting dilution polymerase chain reaction (PCR). We evaluated this assay prospectively in 52 renal transplant patients from whom a total of 495 serial blood samples were collected. The samples scored HCMV positive by qualitative PCR had the levels of HCMV DNA determined by end-point dilution-PCR. All patients were HCMV DNA positive during the monitoring period and a diagnosis of symptomatic infection was made for 4 of 52 patients. In symptomatic patients the geometric mean of the highest level of HCMV DNAemia was 152,000 copies per $10^{6}$ leukocytes, while for the asymptomatic group this value was 12,050 . Symptomatic patients showed high, protracted HCMV DNA levels, whereas asymptomatic patients demonstrated intermittent low or moderate levels. Using a cut-off value of 100,000 copies per $10^{6}$ leukocytes, the limiting dilution assay had sensitivity of $100 \%$, specificity of $92 \%$, a positive predictive value of $43 \%$ and a negative predictive value of $100 \%$ for HCMV disease. In this patient group, there was universal HCMV infection but relatively infrequent symptomatic HCMV disease. The two patient groups were readily distinguished by monitoring with the limiting dilution assay, an extremely simple technology immediately applicable in any clinical laboratory with PCR capability.

\section{Key words}

- Polymerase chain reaction

- Human cytomegalovirus

- Renal transplant

- Diagnosis

- Viral load 


\section{Introduction}

Human cytomegalovirus (HCMV) infection is a major cause of morbidity in immunosuppressed transplant recipients but, for the most part, it is a clinically silent infection in normal individuals (1). In developing countries approximately $100 \%$ of individuals have been infected with HCMV. Thus, in such locations it may be assumed that virtually all transplant donors and recipients will be HCMV positive since individuals generally maintain the virus in a latent form for life. This situation is clinically relevant since reactivation of an existing infection during immunosuppression is less likely to lead to symptomatic disease than a new infection $(1,2)$. Thus, transplant programs in developing countries face a situation where detectable HCMV infection immediately following organ transplant is expected to be extremely frequent, but where symptomatic disease may be relatively rare. In this situation, diagnostic methodologies that permit silent infections to be distinguished from those that are likely to cause disease are of great importance. Furthermore, given the limited resources available for health care in most developing countries, both the sparing use of prophylactic chemotherapy and the simplicity and cost of the diagnostic assay are important considerations. Thus, the development of cost effective methods that might allow the rational use of preemptive chemotherapy in such situations is a priority.

The quantification of HCMV infection using the polymerase chain reaction (PCR) appears to be a powerful option for distinguishing transplant patients with low level HCMV infections from those with clinically relevant infections requiring treatment. Several PCR-based methods for the assessment of HCMV viral load have been reported, including semi-quantitative analysis, such as end-point dilution, or quantitative competitive PCR. Irrespective of the use of semiquantitative or quantitative methods, there is evidence that the quantitation of HCMV genomes permits the differentiation between clinically relevant symptomatic HCMV infections and clinically unimportant CMV DNAemia (3-6). Competitive methods are proving to be the most accurate for quantification by PCR, but they are technically difficult to perform and to use routinely in clinical laboratories. In contrast, semi-quantitative methods are more easily applicable to laboratories in which PCR is regularly performed.

In this study we have assessed the use of a semi-quantitative PCR assay for HCMV DNA in renal transplant recipients in Brazil, a developing country where virtually $100 \%$ of both receptors and donors are seropositive for CMV. We have used a technical approach that is extremely simple and cost effective, allowing immediate implementation in any laboratory where basic PCR techniques are established.

\section{Material and Methods}

\section{Subjects and specimens}

Fifty-two consecutive patients submitted to renal transplantation at Hospital Felício Rocho, Belo Horizonte, Brazil, or at Hospital das Clínicas, University of São Paulo, Brazil, from May to July 1996 were included in this study. Blood samples $(5 \mathrm{ml})$ containing EDTA as anti-coagulant were drawn weekly after renal transplantation for a period of up to 12 weeks. A total of 495 samples were collected within 100 days of transplantation. The number of peripheral blood leukocyte (PBL) preparations obtained per patients ranged from 2 to 16, with a mean of 9 samples per patient.

\section{Serology testing}

Cryopreserved $\left(-20^{\circ} \mathrm{C}\right)$ sera from all available donors and recipients were tested for HCMV IgG and IgM antibodies using stan- 
dard indirect ELISA tests.

\section{Clinical evaluation}

HCMV infection was defined as the detection of HCMV DNA in blood and considered asymptomatic when it occurred without clinical symptoms, signs or abnormal laboratory findings. HCMV infection was considered symptomatic when it occurred in conjunction with clinical symptoms or signs compatible with the disease, such as fever $\left(>38^{\circ} \mathrm{C}\right.$ for at least 5 consecutive days) with a leukopenia of $<2,000 / \mathrm{mm}^{3}$ and/or a fall in platelet count $<100,000 / \mathrm{mm}^{3}$, or visceral disease such as pneumonitis or gastrointestinal symptoms with histological confirmation (7).

\section{DNA preparation}

DNA was isolated from PBLs contained in $1 \mathrm{ml}$ of EDTA blood. Erythrocytes were lysed by three rounds of mixing with $1 \mathrm{ml}$ of $10 \mathrm{mM}$ Tris-HCl, pH 7.6, 1 mM EDTA (TE) in a 2.2- $\mathrm{ml}$ microfuge tube and centrifuged for $90 \mathrm{~s}$ at $14,000 \mathrm{~g}$. The final PBL-containing pellet was resuspended in $100 \mu \mathrm{TE}$ and DNA prepared with the RapidPrep ${ }^{\mathrm{TM}} \mathrm{Ge}-$ nomic DNA isolation kit as described by the manufacturer (Pharmacia Biotech, Uppsala, Sweden). The final volume of the DNA preparation was $50 \mu \mathrm{l}$. The DNA concentration of the sample was estimated by comparison with a low mass DNA ladder (Gibco-BRL, Gaithersburg, MD, USA) following application of $2 \mu \mathrm{l}$ to a $1.5 \%$ agarose gel, electrophoresis and ethidium bromide staining. To estimate the number of leukocytes the value of $6 \mathrm{pg}$ was taken as the quantity of DNA per cell. An example of the DNA estimation is shown in Figure 1. For qualitative PCR amplifications $1 \mu$ of the DNA sample was used in all cases. For limiting dilution assays, $5 \mu \mathrm{l}$ of the DNA were first added to an equal volume of water and subsequently 2fold serial dilutions were executed in water.
Two $\mu \mathrm{l}$ of these dilutions were used for PCR amplification.

\section{Polymerase chain reaction}

The quality of the DNA preparation from all samples was checked by amplification of a 110-bp fragment of the $\beta$-globin gene using the primers $\mathrm{PCO}_{3}$ and $\mathrm{PCO}_{4}(8)$. For qualitative HCMV DNA detection, two pairs of oligonucleotide primers specific for the fourth exon of the HCMV immediate early gene (IE) and HCMV late antigen gp64 (LA) were used in a multiplex format to generate fragments of 393 and $136 \mathrm{bp}$, respectively (9).

All PCR reaction mixtures contained 10 $\mathrm{mM}$ Tris, $\mathrm{pH}$ 8.3, $50 \mathrm{mM} \mathrm{KCl,} 200 \mu \mathrm{M}$ each deoxynucleoside triphosphate, $1.5 \mathrm{mM}$ $\mathrm{MgCl}_{2}, 12.5 \mathrm{pmol}$ of each primer and $2 \mathrm{U}$ of Taq DNA polymerase (Cenbiot, Porto Alegre, $\mathrm{RS}$, Brazil) in a final volume of $50 \mu \mathrm{l}$. The thermal cycling conditions included a waxmediated hot start (10), which precluded the initiation of the reaction until the mixture had reached $80^{\circ} \mathrm{C}$. For amplification of HCMV sequences an initial denaturation step
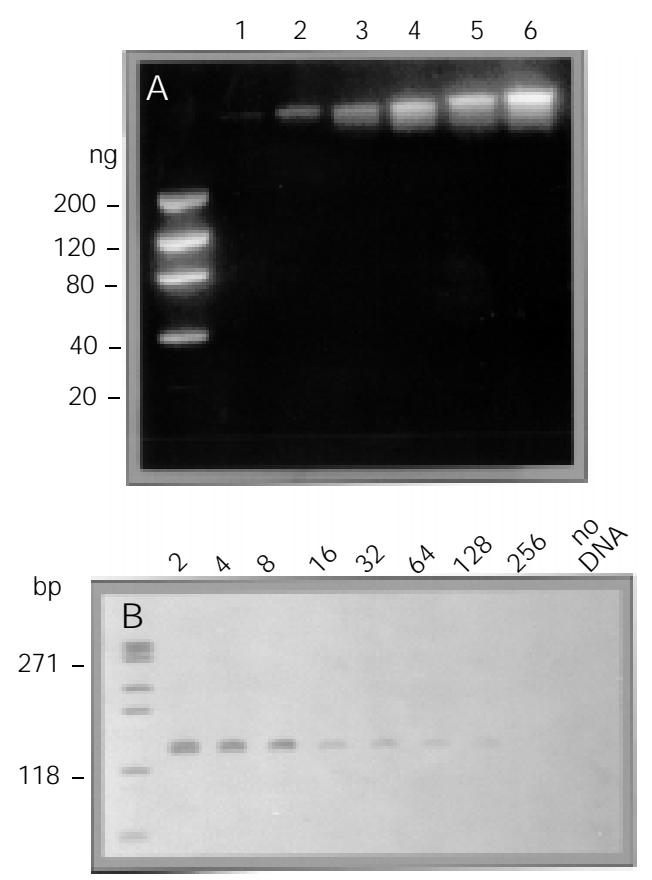

Figure 1 - A, Ethidium bromidestained $1.5 \%$ agarose gel showing the estimation of the DNA concentration in 6 samples by comparison with the low mass DNA ladder. The numbers on the left indicate the quantity of DNA in each band of the standard. The samples were estimated to contain 20, 30, 40, 80, 80 and 100 ng, respectively. B, Silverstained $7 \%$ polyacrylamide gel with amplification products derived from two-fold serial dilutions of one HCMV-positive DNA in which the end-point titer was 128. 
was used at $94^{\circ} \mathrm{C}$ for $3 \mathrm{~min}$, followed by 35 cycles of $30 \mathrm{~s}$ each at $94^{\circ} \mathrm{C}$ and $2 \mathrm{~min}$ at $72^{\circ} \mathrm{C}$. The reaction was completed with a 8 min extension at $72^{\circ} \mathrm{C}$. For amplification of the $B$-globin sequence, the program was the same except that an annealing step at $55^{\circ} \mathrm{C}$ for 1 min was included in all cycles.

All experiments contained two negative controls, one without DNA addition and the other with a human PBL DNA preparation known to be negative for HCMV DNA.

The samples that were HCMV positive by qualitative PCR had their viral load estimated by end-point dilution. Two-fold dilutions of the samples were prepared in water and each dilution was submitted to DNA amplification with the LA primers as described above, in parallel with dilutions of a positive control standard containing 100 copies of the viral genome (9). Four microliters of the PCR products were run on $6 \%$ polyacrylamide gels using a Mini-protean ${ }^{\odot}$ II apparatus (Bio-rad, Hercules, CA, USA). The staining procedure consisted of an initial gel fixation for $3 \mathrm{~min}$ in $10 \%$ ethanol and $0.5 \%$ acetic acid, followed by staining in fixing solution containing $0.2 \%$ silver nitrate for $5 \mathrm{~min}$. After washing in Milli-Q water (Millipore, Bedford, MA, USA) for $2 \mathrm{~min}$, the gels were developed for approximately 5 $\min$ in $3.0 \% \mathrm{NaOH}$ and $0.1 \%$ formaldehyde (11). The end-point was taken as the highest consecutive dilution that yielded a detect-

\begin{tabular}{|c|c|c|c|c|}
\hline \multicolumn{5}{|c|}{$\begin{array}{l}\text { D/R: HCMV serological status (donor/receptor); ND: not } \\
\text { determined. aDays after transplantation. bWith histo- } \\
\text { logical evidence of HCMV in a biopsy of the lesions } \\
\text { obtained by upper endoscopy. }\end{array}$} \\
\hline Patient & $D / R$ & Symptoms & Onset ${ }^{a}$ & Treatment \\
\hline 1 ( ( C39) & $\mathrm{ND} /+$ & Fever/leukopenia & 46 & Ganciclovir \\
\hline 2 (KB47) & $+/+$ & Fever/leukopenia & 25 & None \\
\hline 3 (AS51) & $+/+$ & Fever & 22 & Ganciclovir \\
\hline 4 (ST56) & $\mathrm{ND} /+$ & $\begin{array}{l}\text { Fever/leukopenia/ } \\
\text { gastrointestinal } \\
\text { disease }^{\mathrm{b}}\end{array}$ & 50 & Ganciclovir \\
\hline
\end{tabular}

able PCR product, a detection limit previously shown to contain an average of two viral genomes (9). The estimated number of copies of the HCMV genome per microliter in the initial DNA sample is equal to the dilution factor at the end-point, since $2 \mu \mathrm{l}$ are used for the amplification and the final endpoint is taken as containing two genomes. End-point titers were converted to HCMV DNA copies per $10^{6}$ leukocytes by correcting for the number of leukocytes as estimated above $(12,13)$. Figure $1 \mathrm{~B}$ shows an example of a limiting dilution assay in which the end-point titer was 128. This sample contained 40 ng of DNA per microliter, i.e. 6,660 leukocyte equivalents, as determined by comparison to known standards as described above. Thus, the final estimation of the number of viral genomes per $10^{6}$ leukocytes is $128 \times 10^{6} / 6,600=21,330$.

\section{Results}

Sera from 37 transplant recipients were available for analysis. Thirty-five (95\%) of these patients were CMV seropositive. Donor sera for 14 of these patients were not available. Of the 21 recipients whose donors were available for analysis, 18 received kidneys from CMV-seropositive donors and only three received kidneys from CMV-seronegative donors. The two CMV-seronegative recipients in this study received kidneys from CMV-seropositive donors. A diagnosis of symptomatic HCMV infection was made in 4 out of 52 patients $(7.7 \%)$. The clinical features of these 4 patients are presented in Table 1. The most common clinical symptom was fever and/or leukopenia.

All transplant recipients were found to be HCMV DNA positive at least once during the monitoring period. In each symptomatic case, an increase in HCMV DNA in the blood was detected prior to the onset of symptoms. The frequency of positive results in all patients at different times post-transplantation is shown in Figure 2. The peak of 
HCMV DNA positivity was 6 weeks after transplantation, where $42 \%$ of the patients were positive by qualitative PCR.

We have previously shown that the amplification of the HCMV LA gene fragment, using the primers and conditions selected for the present work, is extremely sensitive and capable of detecting a single viral genome in the assay tube (9). Taking advantage of this optimized PCR protocol, coupled to a highly standardized method of DNA preparation, we found that reproducible estimation of the number of viral genomes per $10^{6}$ leukocytes in the initial sample could be achieved with the simple procedures described. For example, in 232 separate assays the end-point dilution of the positive control was also within a single two-fold dilution. As a further control of reproducibility, the assay was repeated four times with eight of the patients selected to cover the range of estimated copy numbers encountered. The results are shown in Table 2. In all cases the end-point was always plus or minus a single dilution. Thus the estimates are taken as being plus or minus this value.

The estimated HCMV copy number ranged from 60 to more than 300,000 copies/ $10^{6}$ leukocytes. Of a total of 232 quantifications performed, $76 \%$ had low levels of HCMV DNA $\left(<10,000\right.$ copies $/ 10^{6}$ leukocytes), and only $12 \%$ had high levels (>100,000 copies $/ 10^{6}$ leukocytes). Table 3 shows the relation between the blood levels of HCMV DNA and clinical status. The geometric mean of the highest level of HCMV DNA was 152,000 copies $/ 10^{6}$ leukocytes in symptomatic patients. In contrast, in asymptomatic patients this value was 12,050 copies $/ 10^{6}$ leukocytes.

Table 4 shows the clinical relevance of different blood levels of HCMV DNA for the detection of symptomatic infections. Because there were significant gaps in the follow-up of one of the symptomatic patients (patient 1), this analysis was performed considering only the other three symptomatic patients.

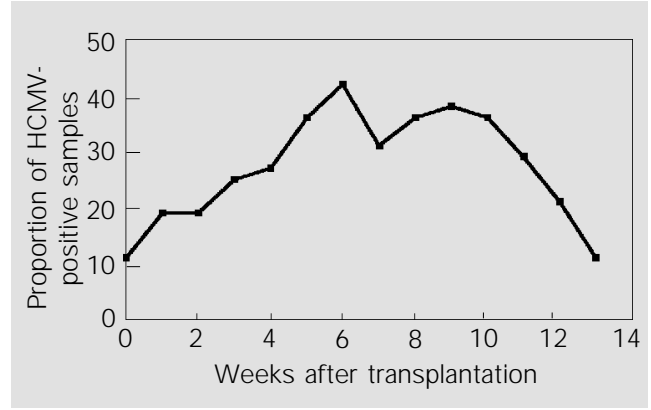

Figure 2 - Proportion of specimens positive for HCMV DNA at different times after renal transplantation.

Table 2 - Reproducibility of end-point determination.

\begin{tabular}{lrrrr}
\hline $\begin{array}{l}\text { Initial end-point } \\
\text { (estimated HCMV } \\
\text { genomes/106 leukocytes) }\end{array}$ & 1st repetition & 2nd repetition & 3rd repetition & 4th repetition \\
& & & & \\
\hline $1: 16(9,600)$ & $1: 16$ & $1: 16$ & $1: 16$ & $1: 16$ \\
$1: 4(2,400)$ & $1: 4$ & $1: 2$ & $1: 4$ & $1: 4$ \\
$1: 8(1,000)$ & $1: 8$ & $1: 8$ & $1: 8$ & $1: 16$ \\
$1: 512(205,000)$ & $1: 128$ & $1: 512$ & $1: 512$ & $1: 512$ \\
$1: 64(154,000)$ & $1: 64$ & $1: 32$ & $1: 128$ & $1: 128$ \\
$1: 16(9,600)$ & $1: 8$ & $1: 16$ & $1: 16$ & $1: 16$ \\
$1: 2(4,800)$ & $1: 2$ & $1: 4$ & $1: 4$ & $1: 4$ \\
$1: 8(19,200)$ & $1: 8$ & $1: 8$ & $1: 4$ & $1: 16$
\end{tabular}

Table 3 - Relation between HCMV quantification and clinical manifestations.

aOnly the highest copy numbers were considered. bOmitted from the calculations in Table 3 due to a significant gap in follow-up of this patient (lower left quadrant of Figure 3).

\begin{tabular}{lccr}
\hline \begin{tabular}{l} 
Viral load (HCMV copies/ $_{10^{6} \text { leukocytes) }}$ \\
\cline { 2 - 4 }
\end{tabular} & $\begin{array}{c}\text { Symptomatic } \\
\text { HCMV infection }\end{array}$ & $\begin{array}{c}\text { Asymptomatic } \\
\text { HCMV infection }\end{array}$ & Total \\
\hline$<10,000$ & 0 & 30 & 30 \\
$10,001-50,000$ & $1^{\mathrm{b}}$ & 10 & 11 \\
$50,001-100,000$ & 0 & 4 & 4 \\
$>100,001$ & 3 & 4 & 7 \\
Total & 4 & 48 & 52
\end{tabular}

Table 4 - Sensitivity, specificity and predictive values of HCMV quantification for HCMV disease.

PPV: Positive predictive value; NPV: negative predictive value. These values were calculated without considering the patient for whom incomplete follow-up data were available (lower left quadrant, Figure 3).

\begin{tabular}{lcccc}
\hline $\begin{array}{l}\text { HCMV DNA level } \\
\text { (copies/106 leukocytes) }\end{array}$ & Sensitivity (\%) & Specificity (\%) & PPV (\%) & NPV (\%) \\
\hline$>10,000$ & 100 & 37 & 18 & 100 \\
$>50,000$ & 100 & 83 & 27 & 100 \\
$>100,000$ & 100 & 92 & 43 & 100
\end{tabular}


Figure 3 - Variation in HCMV viral load over time in PBLs from symptomatic patients during the period of surveillance. Copy numbers are expressed as $\log _{10}$ genomes $/ 10^{6}$ leukocytes. Each graph indicates the main clinical signs and symptoms as well as the therapy used in these patients.
Six patients were treated for rejection episodes and two of them developed HCMV DNA levels of over 100,000 copies $/ 10^{6}$ leukocytes, but did not exhibit symptoms attributable to CMV disease. Although these patients had high HCMV levels in blood, the results suggest that the activation of the virus following anti-rejection therapy had no clinical significance in these patients.

The time course of infection of the 4 symptomatic and of 4 asymptomatic patients is shown in Figures 3 and 4. The former group had high, protracted HCMV DNA levels, whereas the latter had intermittent or transient, low or moderate, levels of HCMV DNA in their blood. The point at which the symptomatic patients became IgM positive, confirming diagnosis of HCMV infection, is indicated in Figure 3.

\section{Discussion}

HCMV disease is a major cause of clinical complications in renal transplant patients, thus requiring careful monitoring for viral
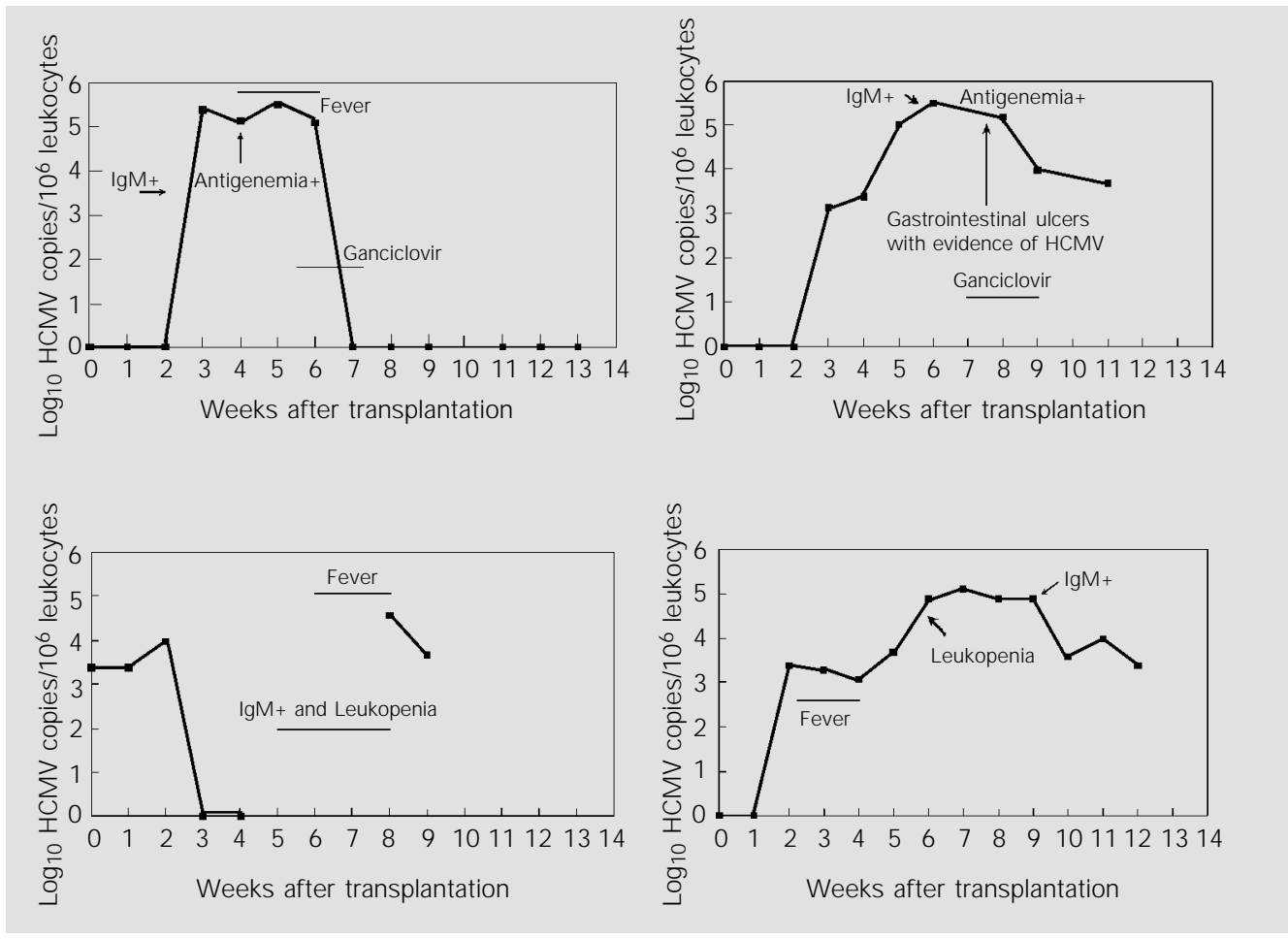

infection (14-17). Recently, several studies have suggested that viral load in blood or urine is the main determinant of clinical manifestations $(3,4,15,17)$ and quantitative or semi-quantitative assays are warranted to identify patients who require antiviral treatment. All of these studies were performed, however, in developed countries with relatively high frequencies of seronegative transplant recipients who are more prone to clinically significant HCMV disease following transplantation. Therefore we sought to establish whether viral load, estimated by a simple and low-cost assay, would also be applicable to identify individuals at risk in the setting of transplant services in a developing country, where virtually all donors and recipients are HCMV seropositive.

Our results demonstrate that all patients exhibited HCMV DNA in blood during the post-transplantation period, thus showing that under our conditions qualitative PCR is not suitable for monitoring renal transplant patients. A similar conclusion was reached in a study in another locality with a high HCMV 
seropositive rate (18). In various studies undertaken in developed countries, where the proportion of renal transplant recipients with evidence of blood HCMV DNA in the posttransplant period is around $50 \%$, qualitative PCR has also been reported to be associated with a low predictive value for the development of HCMV disease $(5,13)$. Peiris et al. (5) reported a $27 \%$ predictive value of HCMV qualitative PCR when analyzing 77 renal transplant patients. In a different study in which a total of $476 \mathrm{HCMV}$ qualitative PCR assays were performed on samples from 134 solid abdominal organ recipients, the positive predictive value was $55 \%$ (19). Because our predictive value for symptomatic HCMV disease would be even lower than in the previous reports, we focused our attention on a semi-quantitative HCMV PCR assay to find a better indicator for monitoring HCMV disease at a lower cost.

Despite the higher frequency of detection of HCMV DNA in the patients studied here, only $7.7 \%$ developed disease. This is in contrast to other studies, in which the inci-
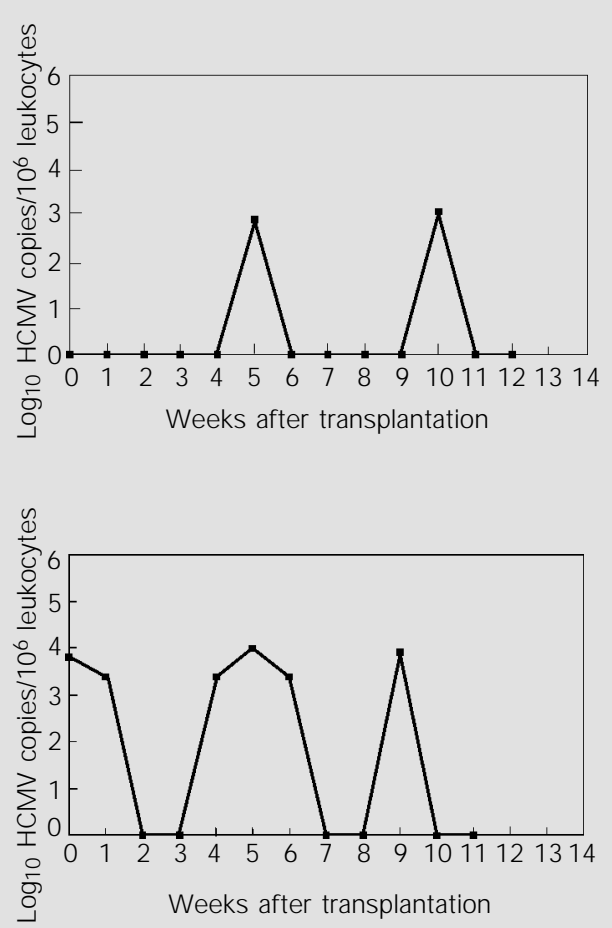

dence of HCMV disease, considering all donor/receptor (D/R) serological categories, is up to $25 \%(3,5,20)$. The lower incidence of the present population may reflect the fact that in this study the majority of recipients were seropositive, in contrast with other studies in which the number of D+/R-patients was at least $20 \%$ (21). In the present study, two seronegative patients received organs from seropositive donors but did not develop symptomatic CMV infection. This observation is consistent with that made by others who have found that, although D+/Rpatients are at a higher risk for developing HCMV disease, not all such patients do so. Indeed, a study conducted on British patients showed that recipient seropositivity had an apparent protective effect against disease when analyzed by univariate logistic regression analysis. However, statistical significance was not maintained when viral load or viremia was controlled for in a multivariate analysis (17).

Our results show substantial variations in HCMV load over time and among different
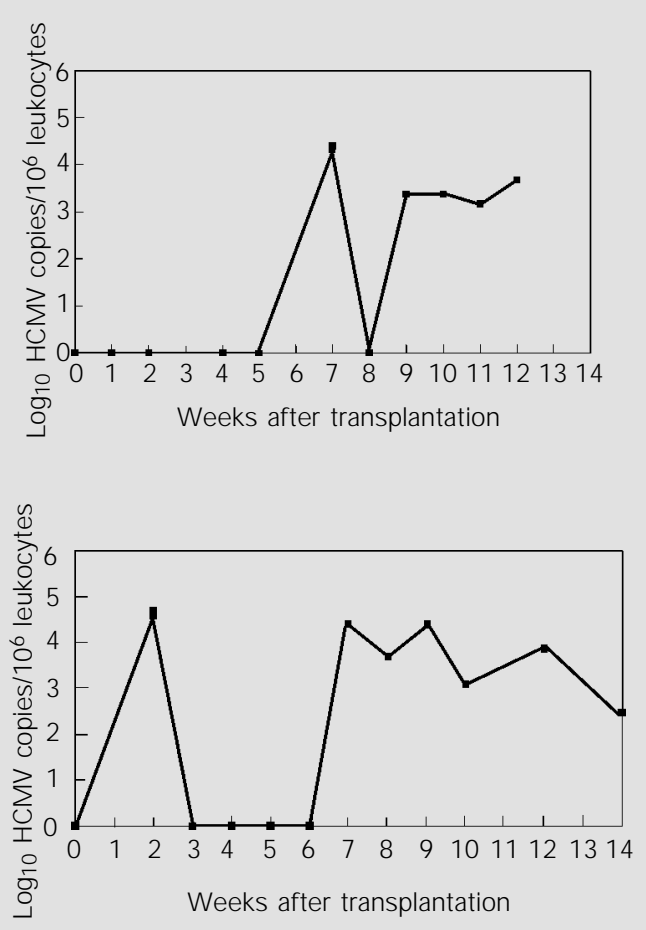

Figure 4 - Variation in HCMV viral load over time in PBLs from asymptomatic patients during the period of surveillance. Copy numbers are expressed as $\log _{10}$ genomes $/ 10^{6}$ leukocytes. 
patients. The mean values of maximum viral load detected in PBLs from asymptomatic versus symptomatic patients differed by more than $10^{5}$ copies $/ 10^{6}$ leukocytes. The analysis of the temporal course of HCMV DNA in symptomatic HCMV patients showed that in the majority of patients viral levels $>100,000$ copies $/ 10^{6}$ leukocytes were reached before or at the onset of clinical symptoms. This indicates that early diagnosis can be achieved using a cut-off approach for semi-quantitative HCMV PCR. We found that an HCMV DNA level higher than 100,000 copies $/ 10^{6}$ leukocytes in a febrile patient is strongly suggestive of symptomatic HCMV infection. The positive predictive value for CMV disease of a viral load of more than 100,000 HCMV copies $/ 10^{6}$ leukocytes for subsequent disease was $43 \%$, thus permitting the identification of a subset of patients in which the probability of symptomatic disease is higher. This viral load test may lead to a more rational use of antiviral prophylaxis in this population. The sensitivity and specificity of the estimation of viral load reported here for HCMV disease using a cut-off of 100,000 copies per $10^{6}$ leukocytes (100 and 92\%, respectively) is in agreement with recent data reported by others for solid organ transplant recipients using antigenemia (18) or quantitative PCR (22-24).

The importance of monitoring these patients weekly must be stressed. Indeed, for optimal monitoring even more frequent testing may be warranted, particularly in cases where anti-rejection therapy is applied. In the patient shown in the upper left quadrant in Figure 3 who had received anti-rejection therapy, the number of viral genomes increased from an undetectable level to more than 100,000 copies within the period of one week.

The semi-quantitative method used in this study is extremely cost-effective (our estimate for all the reagents required for a single assay is less than $\$ 10$ ) and readily applicable in clinical laboratories that perform PCR regularly. Results can be provided in one day, allowing fast diagnosis of HCMV infection. The use of total PBLs for HCMV detection and quantification simplifies the preparation of DNA because they are easily recovered from whole blood.

The clinical application of this test is facilitated by the substitution of the ethidium bromide-stained agarose gels with polyacrylamide gels stained with silver. Silver staining is approximately one hundred times more sensitive than ethidium bromide staining and avoids the need for transillumination and photography, since these gels are conveniently dried and stored as a permanent record of the diagnosis. One of the main disadvantages of the use of silver staining has been that it is too laborious for routine use. This problem has been recently overcome by a method that shortens the staining to approximately $15 \mathrm{~min}$ with the use of very simple reagents (11). In addition, the application of this test was facilitated through the use of electrophoresis against molecular mass ladder to control for variations of template concentration rather than performing for example, ß-globin PCR on serial dilutions, thus significantly simplifying the approach for routine use.

Alternatives to the use of quantitative DNA methodologies are being explored for the quantification of HCMV infections. Among these, antigenemia is the best developed and characterized (25). Ongoing comparisons between DNA quantification and antigenemia in São Paulo suggest that the two methodologies provide data of equal clinical value and that the choice of diagnostic approach will be made on technical grounds and according to the preference of individual diagnostic laboratories. The advantage of PCR-based assays is that they can be easily assimilated in laboratories where PCR is already being done for other purposes without significant investment in training.

On the basis of the data reported here, it appears that limiting dilution PCR may be useful in monitoring viral load in transplant patients in geographical areas with extremely high HCMV prevalence. 


\section{References}

1. Ranjan D, Burke G, Esquenazi V, Milgrom M, Koleitat N, Roth D, Gomez C, Olson L, Babischkin S, Gharagozloo H \& Miller J (1991). Factors affecting the ten-year outcome of human renal allografts. The effect of viral infections. Transplantation, 51: 113-117.

2. Grundy JE, Lui SF, Super M, Berry NJ , Sweny P, Fernando ON, Moorhead J \& Griffiths PD (1988). Symptomatic infection in seropositive kidney recipients: reinfection with donor virus rather than reactivation of recipient virus. Lancet, ii: 132-135.

3. Kühn J E, Wendland T, Schäfer P, Möhring $K$, Wieland $U$, Elgas $M$ \& Eggers $H J$ (1994). Monitoring of renal allograft recipients by quantitation of human cytomegalovirus genomes in peripheral blood leukocytes. J ournal of Medical Virology, 44: 398-405.

4. Fox J C, Kidd IM, Griffiths PD, Sweny P \& Emery VC (1995). Longitudinal analysis of cytomegalovirus load in renal transplant recipients using a quantitative polymerase chain reaction: correlation with disease. J ournal of General Virology, 76: 309-319.

5. Peiris J SM, Taylor CE, Main J, Graham K \& Madeley CR (1995). Diagnosis of cytomegalovinus (CMV) disease in renal allograft recipients: the role of semiquantitative polymerase chain reaction. Nephrology, Dialysis, Transplantation, 10: 11981205.

6. Drouet E, Colimon R, Michelson S, Fourcade N, Niveleau A, Ducerf C, Boibieux A, Chevallier $M$ \& Denoyel $G$ (1995). Monitoring levels of human cytomegalovirus DNA in blood after liver transplantation. J ournal of Clinical Microbiology, 33: 389-394.

7. Ljungman P \& Plotkin S (1995). Workshop on CMV disease: definitions, clinical severity scores and new syndromes. Scandinavian J oumal of Infectious Diseases, 99 (Suppl): 87-89.

8. Saiki RK, Gelfand DH, Stoffel S, Scharf SJ , Higuchi R, Horn GT, Mullis KB \& Erlich HA (1988). Primer-directed enzymatic amplification of DNA with a thermostable DNA polymerase. Science, 239: 487-491.

9. Caballero OL, Menezes CL, Costa MC, Fernandes SC, Anacleto TM, Oliveira RM, Viotti EA, Távora ER, Vilaça SS, Sabbaga
E, Paula FJ, Villa LL \& Simpson AJ G (1997). A single-step PCR protocol for diagnosis and monitoring of human cytomegalovirus infection in renal transplant recipients. J oumal of Clinical Microbiology, 35: 3192-3197.

10. Chou Q, Russel M, Birch DE, Raymond J \& Bloch W (1992). Prevention of pre-PCR mis-priming and primer dimerization improves low-copy-number amplifications. Nucleic Acids Research, 20: 1717-1723.

11. Sanguinetti CJ, Dias Neto E \& Simpson AJ G (1994). Rapid silver staining and recovery of PCR products separated on polyacrylamide gels. Biotechniques, 17: 915-919.

12. Sykes PJ , Neoh SH, Brisco MJ , Hughes E, Condon J \& Morley AA (1992). Quantitation of targets for PCR by use of limiting dilution. Biotechniques, 13: 444-449.

13. Kulski J K (1994). Quantitation of human cytomegalovirus DNA in leukocytes by end-point titration and duplex polymerase chain reaction. J ournal of Virological Methods, 49: 195-208.

14. Gerna G, Zipeto D, Parea M, Revello MG, Silini E, Percivalle E, Zavattoni M, Grossi P \& Milanesi G (1991). Monitoring of human cytomegalovirus infections and ganciclovir treatment in heart transplant recipients by determination of viremia, antigenemia and DNAemia. J oumal of Infectious Diseases, 164: 488-498.

15. Gerdes J C, Spees EK, Fitting K, Hiraki M, Sheehan M, Duda D, J anvi T, Roehl C \& Robertson AD (1993). Prospective study utilizing a quantitative polymerase chain reaction for detection of cytomegalovirus DNA in the blood of renal transplant patients. Transplantation Proceedings, 25: 1411-1413.

16. Falagas ME \& Snydman DR (1995). Recurrent cytomegalovirus disease in solidorgan transplant recipients. Transplantation Proceedings, 27: 34-37.

17. Cope AV, Sweny P, Sabin C, Rees L, Griffiths PD \& Emery VC (1997). Quantity of cytomegalovirus viruria is a major risk factor for cytomegalovirus disease after renal transplantation. J ournal of Medical Virology, 52: 200-205.

18. Lo CY, Ho KN, Yuen KY, Lui SL, Li FK, Chan TM, Lo WK \& Cheng IK (1997). Diagnosing cytomegalovirus disease in
CMV seropositive renal allograft recipients: A comparison between the detection of CMV DNAemia by polymerase chain reaction and antigenemia by CMV pp65 assay. Clinical Transplants, 11: 286293.

19. Abecassis MM, Koffron AJ, Kaplan B, Buckingham M, Muldoon J P, Cribbins AJ , Kaufman DB, Fryer J P, Stuart J \& Stuart FP (1997). The role of PCR in the diagnosis and management of CMV in solid organ recipients: what is the predictive value for the development of disease and should PCR be used to guide antiviral therapy? Transplantation, 63: 275-279.

20. Hokeberg I, Eriksson BM, ZweygbergWirgart B, Tufvesson G, Olding-Stenkvist E \& Grillner L (1995). Diagnostic markers and risk factors of cytomegalovirus infection and disease in renal allograft recipients. Scandinavian J ournal of Infectious Diseases, 27: 435-440.

21. Schnitzler MA, Woodward RS, Brennan DC, Spitznagel EL, Dunagan WC \& Bailey TC (1997). The effects of cytomegalovirus serology on graft and recipient survival in cadaveric renal transplantation: implications for organ allocation. American J oumal of Kidney Diseases, 29: 428434.

22. Mendez J, Espy M, Smith TF, Wilson J, Wiesner R \& Paya CV (1998). Clinical significance of viral load in the diagnosis of cytomegalovirus disease after liver transplantation. Transplantation, 64: 14771481

23. Zaia J A, Gallez-Hawkins MG, Tegtmeier BR, ter Veer A, Li X, Niland J C \& Forman SJ (1997). Late cytomegalovirus disease in marrow transplantation is predicted by virus load in plasma. J ournal of Infectious Diseases, 176: 782-785.

24. Imbert MBM, Cantarovich D, Ferre AV, Richet B, Soulillou J P \& Billaudel S (1997). Usefulness of DNA viral load quantification for cytomegalovirus disease monitoring in renal and pancreas/renal transplant recipients. Transplantation, 63: 14761481

25. Boeckh M \& Boivin G (1998). Quantitation of cytomegalovirus: Methodologic aspects and clinical applications. Clinical Microbiology Reviews, 11: 533-554. 